\title{
DETERMINATION OF THE RELATIVE OZONE AND PAN DEPOSITION VELOCITIES AT NIGHT
}

\author{
P. B. Shepson ${ }^{1}$, J. W. Bottenheim ${ }^{1,2}$, D. R. Hastie ${ }^{1}$, and A. Venkatram ${ }^{3}$
}

Abstract. A series of measurements of PAN and ozone was conducted during summer at three rural sites in Canada: Egbert and Dorset, Ontario, and Kejimkujik, Nova Scotia. For nights when a stable surface inversion layer forms, ozone and PAN at the surface are found to undergo first order decay, assumed to be due only to dry deposition. Analysis of the measurement data leads to determination of the relative dry deposition velocities. For all three sites, we find that $\mathrm{V}_{\mathrm{d}}\left(\mathrm{O}_{3}\right) / \mathrm{V}_{\mathrm{d}}(\mathrm{PAN})=0.42 \pm 0.19$, at night. This ratio is roughly a factor of 5-6 times smaller than previously assumed. This smaller relative deposition velocity ratio can have a significant impact on model estimations of PAN concentrations near the surface. We estimate that for these sites, the PAN deposition velocity is at least $0.5 \mathrm{~cm} / \mathrm{s}$, and may be greater during daytime. This can have a significant impact on the tropospheric lifetime of PAN.

\section{Introduction}

There is increasing interest in development of computer models that simulate tropospheric oxidant concentrations, in light of the steady increase in global background $\mathrm{O}_{3}$ concentrations, and the fact that regional episodic $\mathrm{O}_{3}$ concentrations often exceed local standards. Testing and evaluation of these models requires measurement data for species other than $\mathrm{O}_{3}$, predictions for which are not sensitive to the details of the model chemistry. One important oxidant that provides a more robust test of model performance is peroxyacetyl nitrate (PAN). PAN is produced from the atmospheric oxidation of hydrocarbons in the presence of $\mathrm{NO}_{\mathrm{x}}$, and is thought to contribute significantly to the global transport and storage of $\mathrm{NO}_{\mathrm{x}}$ (Singh and Hanst, 1981).

Measurement campaigns aimed at understanding tropospheric chemistry are most often conducted at the surface, for obvious reasons of convenience. However, the frequent presence of a stable nocturnal boundary layer (NBL) with shallow mixing heights can result in significant depletion of surface layer species concentrations at night due to dry deposition. When the noctumal inversion breaks up in the moming due to surface heating, downward mixing of undepleted pollutants from aloft restores the surface layer concentrations to values more representative of those in a well mixed planetary boundary layer (PBL). Thus the diumal variation of species that undergo surface deposition can be significantly influenced by the formation and breakup of the NBL (Garland and Penkett, 1976; Broder et al., 1981; Fehsenfeld et al., 1983). We have recently conducted simultaneous measurements of PAN and ozone at three surface sites in Ontario, Canada, where we observe relatively rapid losses for these species at night, particularly under

'Department of Chemistry and Centre for Atmospheric Chemistry, York University, 4700 Keele Street, North York, Ontario, Canada, M3J 1P3.

${ }^{2}$ Atmospheric Environment Service, Environment Canada, Downsview, Ontario, Canada

${ }^{3}$ ENSR Consulting and Engineering, 1220 Avenida Acaso, Camarillo, CA, USA 93010

Copyright 1992 by the American Geophysical Union.

Paper number 92GL01118

0094-8534/92/92GL-01118\$03.00 clear sky high pressure conditions where stable NBLs tend to form. Under such conditions, we typically observe significantly faster decay for PAN, relative to ozone (Shepson et al, 1992).

There have previously been two studies where PAN and ozone deposition velocities were measured for the same surface. Garland and Penkett (1976) conducted laboratory measurements of PAN deposition velocities to grass and soil, and obtained average values of $\pi 0.25 \mathrm{~cm} / \mathrm{s}$ for both surfaces. Corresponding ozone deposition velocities for grass and soil were 0.51 and $1.6 \mathrm{~cm} / \mathrm{s}$, respectively. Studies of PAN and $\mathrm{O}_{3}$ deposition to an alfalfa canopy, conducted by Hill (1971), indicated deposition velocities of 0.75 and $1.7 \mathrm{~cm} / \mathrm{s}$, respectively. Thus, these two studies indicate that the ratio $\mathrm{V}_{\mathrm{d}}\left(\mathrm{O}_{3}\right) / \mathrm{V}_{\mathrm{d}}(\mathrm{PAN})$ ranges from $\sim 2-6$. Current model formulations use, or compute, based on diumally varying surface resistances, $\mathrm{O}_{3}$ and PAN deposition velocities that are consistent with these observed ratios (e.g. Dodge, 1989; Kasting and Singh, 1986; Kanakidou et al., 1991).

In contrast to the assumed relative deposition rates for these two species, we have consistently observed significantly faster apparent deposition rates for PAN relative to $\mathrm{O}_{3}$ in a number of rural sites in Canada. In this paper we present results of our analysis of the relative $\mathrm{O}_{3}$ and PAN deposition velocities at these sites.

\section{Experimental Methods}

Measurements of PAN and $\mathrm{O}_{3}$ were made during several different measurement campaigns at the surface at three rural sites in Canada: Egbert, and Dorset, Ontario, and Kejimkujik, Nova Scotia. Measurements at Egbert were conducted at the Centre for Atmospheric Research Experiments (CARE), operated by Environment Canada, located in a rural/agricultural area $-60 \mathrm{~km}$ northwest of Toronto. The Dorset site is an APIOS (Air Pollution in Ontario Study) air monitoring station, located in a shallow valley, in a mixed deciduous/coniferous $(75 \% / 25 \%)$ forested area, $-175 \mathrm{~km}$ northeast of Toronto. The Kejimkujik site is a CAPMON (Canadian Air and Precipitation Monitoring Network) station, located in a forest clearing ( $25 \%$ deciduous $/ 75 \%$ coniferous) in Kejimkujik National Park, Nova Scotia, ca. $150 \mathrm{~km}$ to the WSW of the city of Halifax, N.S. Measurements of PAN and $\mathrm{O}_{3}$ have been conducted at that site on a year-round basis since 1984 (Brice et al., 1988). The Egbert and Dorset sites were participating sites during the Eulerian Model Evaluation Field Study, conducted during 1988 and 1990. For both these sites, stable NBLs are known to exist during clear high pressure conditions, leading to significant losses for species under the inversion (D.R. Hastie et al., unpublished data, 1992; Hoff et al., 1989).

PAN was measured hourly at each site by gas chromatography with electron capture detection, for Dorset as described by Blanchard et al. (1990) and for Egbert and Kejimkujik as described by Brice et al. (1988). The accuracy of the measurements is estimated at $\pm 20 \%$, and the precision is estimated to be $\pm 5 \%$, for concentrations that are at least 3 times the detection limit of $0.010 \mathrm{ppb}$. Ozone was measured by UV absorption using Dasibi Model AH-1008 or TECO Model 049 Monitors. For all sites, measurements were made using inlets situated $\sim 3 \mathrm{~m}$ above the ground.

\section{Data Analysis}

For relatively stable conditions where a low lying nocturnal inversion exists, we believe that the dominant loss 


\section{Model for Dry Deposition}

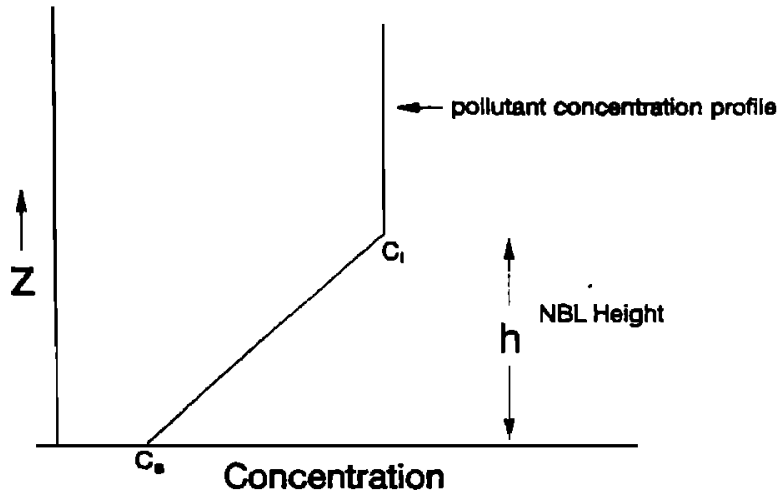

Fig. 1. Assumed Nocturnal Pollutant Profile.

process for both PAN and $\mathrm{O}_{3}$ at the surface is dry deposition. For a typical $\mathrm{O}_{3}$ concentration of $30 \mathrm{ppb}$, the lifetime of NO with respect to reaction with $\mathrm{O}_{3}$ is on the order of 1 minute, so that NO at night is rapidly removed, and loss of $\mathrm{O}_{3}$ by this reaction becomes unimportant, as long as there is no significant surface source of NO. The $\mathrm{NO}_{\mathrm{x}}$ concentrations are typically on the order of 1-4 ppb, and thus the NO titration reaction does not significantly deplete $\mathrm{O}_{3}$ at night. For Dorset we have found the soil NO flux to be $s 2 \mu \mathrm{g} / \mathrm{m}^{2} \mathrm{~h}$, corresponding to a maximum emission rate of 7 $\mathrm{ppt} / \mathrm{h}$ for a $150 \mathrm{~m}$ mixing height. Given the relatively high $\mathrm{NO}_{\mathrm{x}}$ concentration at the time the NBL forms, the soil NO flux would not contribute significantly. Thus we believe that the $\mathrm{O}_{3}+\mathrm{NO}$ reaction is an unimportant loss mechanism for $\mathrm{O}_{3}$ at night at these sites. The relatively small rate coefficients for $\mathrm{O}_{3}$ reaction with alkenes coupled with the fact that their concentrations in rural areas are normally much smaller than that of $\mathrm{O}_{3}$ makes reaction with alkenes an unimportant loss process, relative to dry deposition.

The thermal decomposition of PAN, the dominant removal term in the daytime, also becomes suppressed at night, due to the large $\mathrm{NO}_{2} / \mathrm{NO}$ ratio, and lower temperatures. In the presence of NO, PAN thermal decomposition results in PAN loss via reactions 1 and 2 below.

$$
\begin{aligned}
\mathrm{CH}_{3} \mathrm{C}(\mathrm{O}) \mathrm{OONO}_{2} & -\mathrm{CH}_{3} \mathrm{C}(\mathrm{O}) \mathrm{OO}+\mathrm{NO}_{2} 1,-1 \\
\mathrm{CH}_{3} \mathrm{C}(\mathrm{O}) \mathrm{OO}+\mathrm{NO} & \rightarrow \mathrm{CH}_{3} \mathrm{C}(\mathrm{O}) \mathrm{O}+\mathrm{NO}_{2}{ }^{2}
\end{aligned}
$$

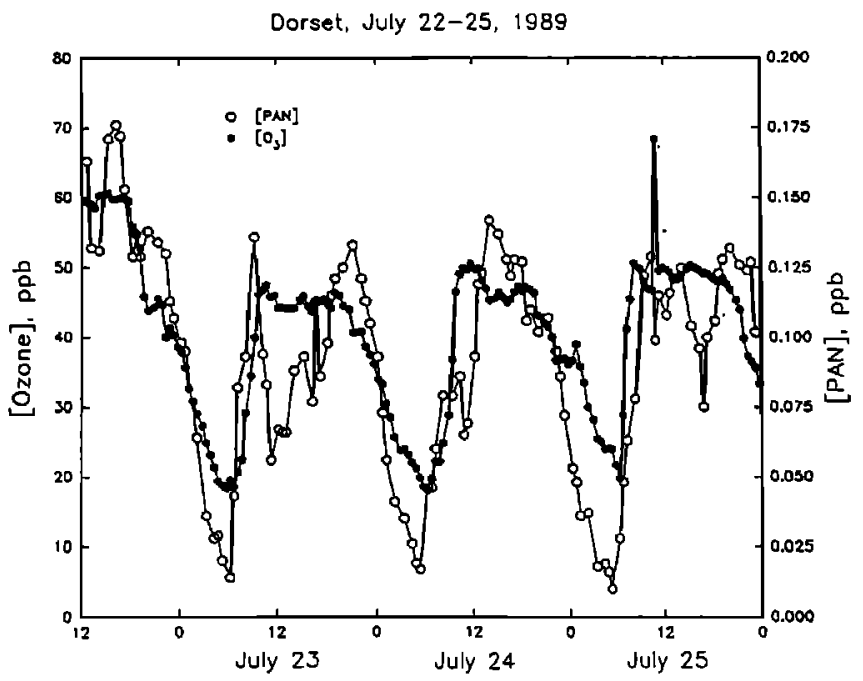

Fig. 2. PAN and Ozone Concentrations Measured at Dorset, Ont., July 22-25, 1989.
Thus although PAN loss occurs via reaction 2, the PAN lifetime does not depend on the absolute NO concentration, but on the ratio $\left[\mathrm{NO}_{2}\right] /[\mathrm{NO}]$. The thermal lifetime for PAN in the presence of $\mathrm{NO}$ and $\mathrm{NO}_{2}$ is given by equation (I):

$$
\tau=\left(k_{1}-\frac{k_{1}}{1+\frac{k_{2}[N O]}{k_{-1}\left[N O_{2}\right]}}\right)^{-1}
$$

At night the ratio $\mathrm{NO}_{2} / \mathrm{NO}$ is typically quite large, i.e. 220 . For example, for the July 17, 1989 Dorset case discussed below, the $\mathrm{NO}_{2} / \mathrm{NO}$ ratio was roughly 25 . For a median temperature for that night of $9^{\circ} \mathrm{C}$, this corresponds to an effective lifetime of 7 days. The $\left[\mathrm{NO}_{2}\right] /[\mathrm{NO}]$ ratio did not decrease significantly during the night since, as stated above, the surface NO source was very small. The total NO, concentration decreased from $\sim 4$ to -3 ppb over the night time PAN decay period. For the cases studied here the observed decay times for PAN were typically on the order of 3-6 hours, and thus we believe that thermal decomposition of PAN is relatively unimportant. Thus the dominant loss term for PAN at night under the NBL will also be dry deposition.

For the conditions described above, we can construct a simple model for the time variation of PAN and $\mathrm{O}_{3}$, whose vertical profiles we assume are as shown in Figure 1. Species concentrations in the horizontally homogeneous boundary layer can be described by:

$$
\frac{\partial C}{\partial t}=-\frac{\partial F}{\partial z}
$$

where $\mathrm{C}$ is the concentration, and $\mathrm{F}$ is the flux of the species in the vertical direction $z$. Integrating Equation (II) over the height of the boundary layer yields:

$$
-\int_{0}^{h} \frac{\partial C}{\partial t} \cdot d z=F_{s}-F_{h}
$$

where $F_{s}$ is the flux at the surface, and $F_{h}$ is the flux at the top of the nocturnal boundary layer. If we make the simplifying assumption that the height of the boundary layer is constant, $F_{b}=0$ since there is no mixing across the top of the NBL. Given the assumption that the concentration profile is linear within the boundary layer,

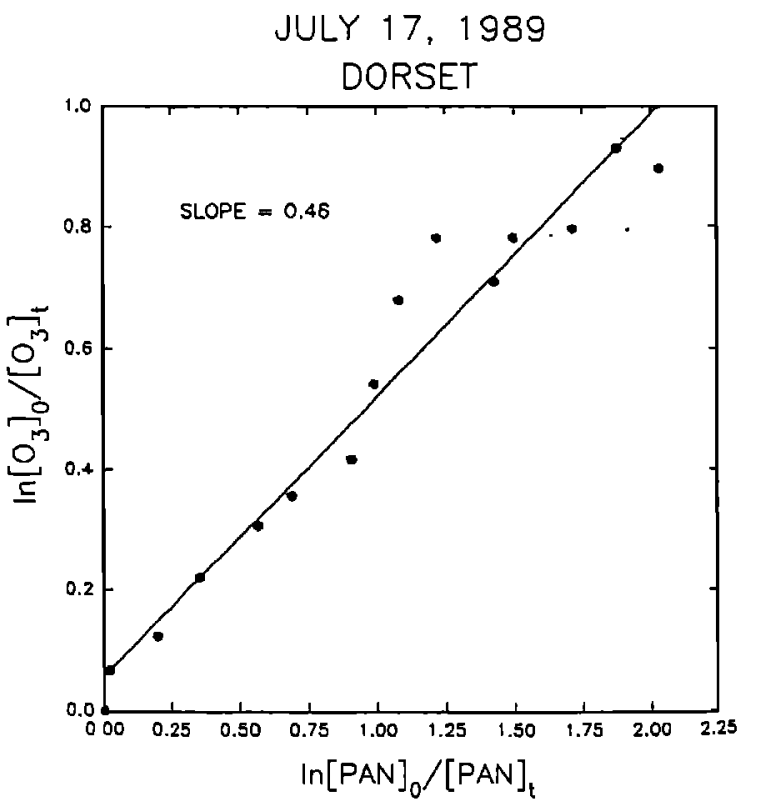

Fig. 3. Plot of Equation (VII) for July 17, 1989, for Dorset, Ontario. 
Table 1. Measured Relative Ozone and PAN Deposition Velocities for Three Rural Sites in Canada.

\begin{tabular}{|c|c|c|c|c|c|c|c|c|}
\hline \multirow[b]{2}{*}{ Date } & \multicolumn{3}{|l|}{ Dorset (1989) } & \multicolumn{2}{|l|}{ Egbert (1988) } & \multicolumn{3}{|c|}{ Kejimkujik } \\
\hline & $\mathrm{V}_{\mathrm{d}}\left\{\mathrm{O}_{3}\right\} / \mathrm{V}_{d}\{\mathrm{PAN}\}$ & $r^{2}$ & Date & $\mathrm{V}_{\mathrm{d}}\left\{\mathrm{O}_{3}\right\} / \mathrm{V}_{\mathrm{d}}\{\mathrm{PAN}\}$ & $r^{2}$ & Date & $\mathrm{V}_{d}\left\{\mathrm{O}_{3}\right\} / \mathrm{V}_{\mathrm{d}}\{\mathrm{PAN}\}$ & $r^{2}$ \\
\hline $7 / 13$ & 0.23 & 0.87 & $8 / 5$ & 1.1 & 0.88 & $5 / 16 / 88$ & 0.23 & 0.96 \\
\hline $7 / 15$ & 0.37 & 0.97 & $8 / 6$ & 0.35 & 0.87 & $5 / 29 / 88$ & 0.52 & 0.96 \\
\hline $7 / 16$ & 0.54 & 0.84 & $8 / 23$ & 0.51 & 0.74 & $5 / 30 / 88$ & 0.47 & 0.94 \\
\hline $7 / 17$ & 0.46 & 0.95 & & & & $7 / 5 / 90$ & 0.31 & 0.85 \\
\hline $7 / 19$ & 0.34 & 0.93 & & & & $7 / 13 / 90$ & 0.50 & 0.91 \\
\hline $7 / 22$ & 0.48 & 0.81 & & & & $7 / 20 / 90$ & 0.52 & 0.98 \\
\hline $7 / 23$ & 0.47 & 0.96 & & & & $8 / 18 / 90$ & 0.23 & 0.72 \\
\hline $7 / 24$ & 0.32 & 0.97 & & & & $8 / 30 / 90$ & 0.39 & 0.81 \\
\hline $7 / 25$ & 0.23 & 0.85 & & & & & & \\
\hline $7 / 30$ & 0.33 & 0.87 & & & & & & \\
\hline Averages: & $0.38 \pm 0.11$ & 0.90 & & $0.65 \pm 0.40$ & 0.83 & & $0.40 \pm 0.12$ & 0.89 \\
\hline
\end{tabular}

$$
\int_{0}^{h} C \cdot d z=\frac{\left(C_{i}+C_{s}\right) \cdot h}{2}
$$

and since $F_{s}=V_{d} \cdot C_{s}$, Equation (III) can be written as:

$$
\frac{\partial C_{s}}{\partial t}=-\frac{2 V_{d}}{h} \cdot C_{s}
$$

We take $C_{i}$ to be the concentration in the late afternoon mixed layer, just as the NBL forms, when $C_{s}=C_{i}$. Then Equation (V) can be integrated to obtain

$$
C_{s}=C_{i} \exp \left[-\frac{2 V_{d}}{h} t\right]
$$

where $t$ is the time from the onset of formation of the nocturnal boundary layer. This Equation indicates that under the conditions assumed, surface concentrations undergo exponential decay, with a first order rate constant equal to $\left(-2 V_{d} / h\right)$. Exponential loss is often observed for these compounds for all three sites during summer, as shown in Figure 2, for a period in July, 1989, at Dorset. Equation (Vi) then forms the basis for an analysis of the data in terms of determination of the relative deposition velocities. From combination of the appropriate form of Equation (VI) for $\mathrm{O}_{3}$ and PAN, we obtain Equation (VII):

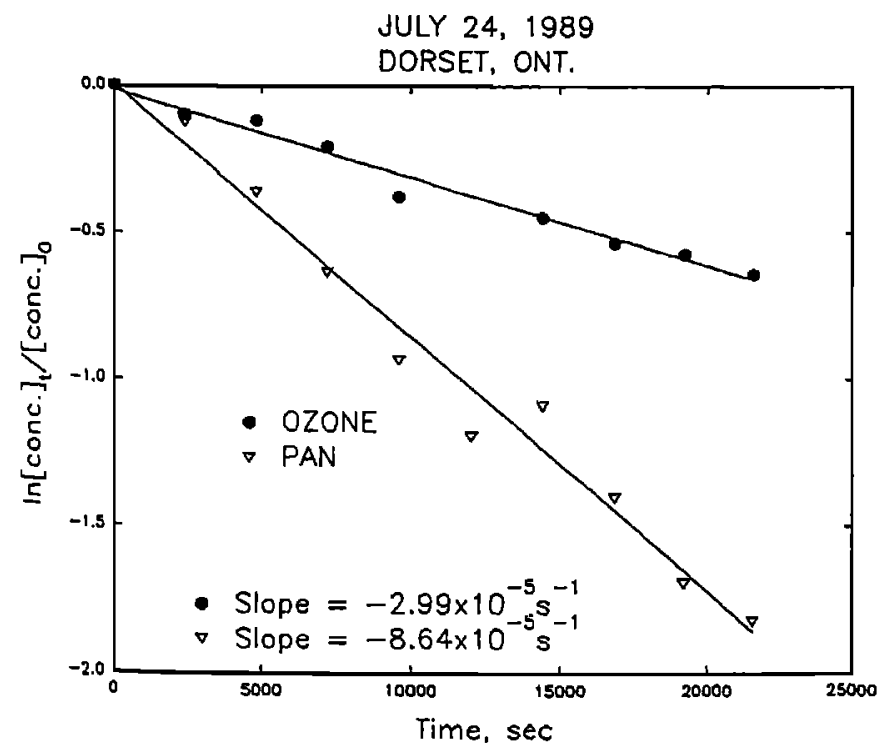

Fig. 4. Plot of First Order Decays of Ozone and PAN, 7/24/89, Dorset, Ont.

$$
\ln \frac{\left[O_{3}\right]_{0}}{\left[O_{3}\right]_{t}}=\frac{V_{d}\left(O_{3}\right)}{V_{d}(P A N)} \ln \frac{[P A]_{0}}{\left[P A M_{t}\right.}
$$

In the following section, we present results of determination of the ratio $\mathrm{V}_{\mathrm{d}}\left(\mathrm{O}_{3}\right) / \mathrm{V}_{\mathrm{d}}$ (PAN) using Equation (VII), for the data from these three sites in the summer, between 1988 and 1990.

\section{Results and Discussion}

For a series of measurements of $\mathrm{O}_{3}$ and PAN between 1988 and 1990, we plotted the left vs. right side of Equation (VII), for the time period between $2000-0600$. We then selected all cases for which ${ }^{2}$ was greater than 0.7 . For these three sites, a total of 21 such cases were found. A sample case is shown in Figure 3 for July 17, 1989, for the Dorset site. The results for all sites are presented in Table 1. As shown in the Table, the average ratio $\mathrm{V}_{d}\left(\mathrm{O}_{3}\right) / \mathrm{V}_{\mathrm{d}}(\mathrm{PAN})$ for all three sites was $0.42 \pm 0.19$.

The results presented in Table 1 indicate that on average the $\mathrm{O}_{3}$ deposition velocity at night is 2.5 times smaller than that for PAN, at these sites, at least for days when both species undergo exponential decay, and are reasonably well correlated. Thus the ratio $\mathrm{V}_{\mathrm{d}}\left(\mathrm{O}_{3}\right) / \mathrm{V}_{\mathrm{d}}(\mathrm{PAN})$ at night appears to be approximately a factor of 5-6 smaller than previously assumed, at least for the type of sites studied here.

It is well known that the $\mathrm{O}_{3}$ deposition velocity has a strong diurnal variability, at least in part due to the increase in surface resistance (for soil, grass, forests) at night (Galbally and Roy, 1980). Colbeck and Harrison (1985) find $\mathrm{O}_{3}$ deposition velocities to grass to range from about $0.1-0.9$ $\mathrm{cm} / \mathrm{s}$. For a variety of sites, the ozone deposition velocity seems to be 2-3 times smaller at night, most typically 0.2-0.3 $\mathrm{cm} / \mathrm{s}$. These observations are consistent with more recent measurements at a forest site near Egbert during August 1988 (Padro et al., 1991), where $\mathrm{V}_{\mathrm{d}}\left(\mathrm{O}_{3}\right)$ was found to be, on average, $-0.25 \mathrm{~cm} / \mathrm{s}$ at night, increasing to $-1 \mathrm{~cm} / \mathrm{s}$ near noon. Our determination of the deposition velocity ratios implies that $\mathrm{V}_{\mathrm{d}}(\mathrm{PAN})$ is on the order of $0.6 \mathrm{~cm} / \mathrm{s}$ at night, for these sites.

For cases where the inversion height, $\mathrm{h}$, is stable and is known, we can estimate the absolute value for $V_{d}$ (PAN). For this analysis, as discussed above, we assume that the initial measurements (when the NBL has formed) represent the PAN concentration at the top of the fully developed NBL, and that the vertical profile is represented by a linear decrease to the values measured at the surtace. Then the first order decay for PAN is given by Equation (VIII):

$$
\ln \frac{[P A M]_{R}}{[P A]_{0}}=\frac{-2 V_{d}(P A N)}{h} t
$$


Thus a plot of $\ln \left\{[\mathrm{PAN}]_{\mathrm{t}} /[\mathrm{PAN}]_{0}\right\}$ vs time (sec) yields a slope equal to $-2 V_{d}($ PAN $) / h$. In Figure 4 we present these first order decay plots for both $\mathrm{O}_{3}$ and PAN, for the July 24, 1989 case at Dorset. For this case the inversion height, as determined using an acoustic sounder, was stable at $125 \pm 12$ $\mathrm{m}$. The slopes observed were $-2.99 \times 10^{-5} \mathrm{~s}^{-1}$, and

$-8.64 \times 10^{-5} \mathrm{~s}^{-1}$, for ozone and PAN, respectively, yielding calculated dry deposition velocities for $\mathrm{O}_{3}$ and PAN of 0.19 and $0.54 \mathrm{~cm} / \mathrm{s}$, respectively. This value for the $\mathrm{O}_{3}$ dry deposition velocity is consistent with other observations at night, as discussed above. However, the value for PAN is a factor of two larger than that reported by Garland and Penkett (1976), and the relative deposition velocities differ by a factor of $-5-6$. However, it is not clear whether the Garland and Penkett conditions apply to day or night conditions. We note that this absolute value of $V_{d}(P A N)$ is dependent on the assumed profile in Figure 1.

We would expect that the PAN deposition velocity may vary diumally in a manner similar to that observed for $\mathrm{O}_{3}$. At Dorset, the relative humidity normally approaches $100 \%$ for nights where there is a stable NBL, as $10 \%$ of the regional surface is water. Both $\mathrm{O}_{3}$ and PAN have very large surface resistances for deposition to water. For $\mathrm{O}_{3}$ the surface resistance for deposition to water is $-14 \mathrm{~s} / \mathrm{cm}$, implying that $\mathrm{V}_{\mathrm{d}}\left(\mathrm{O}_{3}\right)<0.07 \mathrm{~cm} / \mathrm{s}$ (Galbally and Roy, 1980). The deposition velocity for PAN to water has been estimated to be $\sim 0.008 \mathrm{~cm} / \mathrm{s}$ (Kames et al., 1991). Thus if vegetation surfaces become relatively hydrated at night, we might expect the deposition velocity to decrease. In addition, it is well known that the increased stomatal resistance at night significantly impacts on $\mathrm{O}_{3}$ deposition velocities (Colbeck and Harrison, 1985), and may affect PAN deposition as well. Although the nature of the PANvegetation interaction is unknown, this implies that daytime PAN deposition velocities may be even larger than the -0.5 $\mathrm{cm} / \mathrm{s}$ found for night. As this has significant implications for the atmospheric lifetime for PAN, it is clear that measurements of daytime PAN surface fluxes are needed.

\section{Conclusions}

This study has indicated that the deposition velocity of PAN for vegetative surfaces in summer at night is, on average, 2.5 times greater than that for $\mathrm{O}_{3}$. This is a factor of 5-6 greater than previously assumed. Thus PAN loss to the surface may be more important than previously assumed. This can have a significant impact on calculated PAN concentrations for the near surface layers, and therefore computer models may need to incorporate relatively larger PAN deposition velocities. Considering the importance of PAN to the transport of tropospheric $\mathrm{NO}_{\mathrm{O}}$ and resultant photochemical production of ozone, and the scarcity of information regarding PAN deposition rates, it is clear that additional PAN deposition velocity measurements are needed.

Acknowledgements. We thank Dr. K. G. Anlauf (AES) for providing the $\mathrm{O}_{3}$ data for Egbert, and A. Bates, K. W. So, S. Sharma, and A. J. Gallant for various aspects of data acquisition and analysis. We also thank the Ontario Ministry of the Environment and the Natural Science and Engineering Research Council of Canada for financial support.

\section{References}

Blanchard P., Shepson P. B., So K. W., Schiff H. I., Bottenheim J. W., Gallant A. J., Drummond J. W., and Wong P. "A Comparison of Calibration and Measurement Techniques for Gas Chromatographic
Determination of Atmospheric Peroxyacetyl Nitrate (PAN)" Atmos. Environ., 24A, 2839-2846 (1990).

Brice K. A., Bottenheim J. W., Anlauf K. G., and Wiebe H. A. "Long-Term Measurements of Atmospheric Peroxyacetyl Nitrate (PAN) at Rural Sites in Ontario and Nova Scotia; Seasonal Variations and Long-Range Transport" Tellus, 40B, 408-425 (1988).

Broder B., Dütsch H. U., and Graber W. "Ozone Fluxes in the Nocturnal Planetary Boundary Layer Over Hilly Terrain". Atmos. Environ., 15, 1195-1199 (1981).

Colbeck I. and Harrison R. M. "Dry Deposition of Ozone: Some Measurements of Deposition Velocity and of Vertical Profiles to 100 Metres" Atmos. Environ, 19 , 1807-1818 (1985).

Dodge M. C. "A Comparison of Three Photochemical Oxidant Mechanisms" J. Geophys. Res., 94, 5121-5136 (1989)

Fehsenfeld F. C., Bollinger M. J., Liu S. C., Parrish D. D., McFarland M., Trainer M., Kley D., Murphy P. C., and Albritton D. L. "A Study of Ozone in the Colorado Mountains" J. Atmos. Chem., 1, 87-105 (1983).

Galbally I. E. and Roy C. R. "Destruction of Ozone at the Earth's Surface" Quart. J. R. Met. Soc., 106, 559-620 (1980).

Garland J. A. and Penkett S. A. "Absorption of Peroxy Acetyl Nitrate and Ozone by Natural Surfaces" Atmos. Environ., 10, 1127-1131 (1976).

Hill A. C. "Vegetation: A Sink for Atmospheric Pollutants" I Air Pollut. Control Ass., 21, 341-346 (1971).

Hoff R. M., Mickle R. E., Fanaki F., Froude F. A., Amold J., and Markes J. "Vertical Profiles of Ozone and Meteorology at CARE, Egbert" Environment Canada Report ARD-89-009.

Kames J., Schweighoefer S. and Schurath U. "Henry's Law Constant and Hydrolysis of Peroxyacetyl Nitrate (PAN)" I. Atmos. Chem., 12, 169-180 (1991).

Kanakidou M., Singh H. B., Valentin K. M., and Crutzen P. J. "A Two-Dimensional Study of Ethane and Propane Oxidation in the Troposphere" J. Geophys. Res.. 96, $15,395-15,413$ (1991).

Kasting J. F. and Singh H. B. "Nonmethane Hydrocarbons in the Troposphere: Impact on the Odd Hydrogen and Odd Nitrogen Chemistry" J. Geophys. Res., 91, 13,23913,256 .

Padro J., den Hartog G. and Neumann H. H. "An Investigation of the ADOM Dry Deposition Module Using Summertime $\mathrm{O}_{3}$ Measurements Above a Deciduous Forest" Atmos. Environ., 25A, 1689-1704 (1991).

Shepson P. B., Hastie D. R., So K. W., Schiff H. I., and Wong P. "Relationships Between PAN, PPN, and $\mathrm{O}_{3}$ at Urban and Rural Sites in Ontario" Atmos. Environ., 26A, 1259-1270 (1992).

Singh H. B. and Hanst P. L. "Peroxyacetyl Nitrate (PAN) in the Unpolluted Atmosphere: An important Reservoir for Nitrogen Oxides" Geophys. Res. Lett., $\underline{8}$, 941-944 (1981).

${ }^{\mathrm{I}}$ Department of Chemistry and Centre for Atmospheric Chemistry, York University, 4700 Keele Street, North York, Ontario, Canada, M3J 1P3.

${ }^{2}$ Atmospheric Environment Service, Environment Canada, Downsview, Ontario, Canada

${ }^{3}$ ENSR Consulting and Engineering, 1220 Avenida Acaso, Camarillo, CA, USA 93010

(Received: March 11, 1992; accepted: April 29, 1992.) 